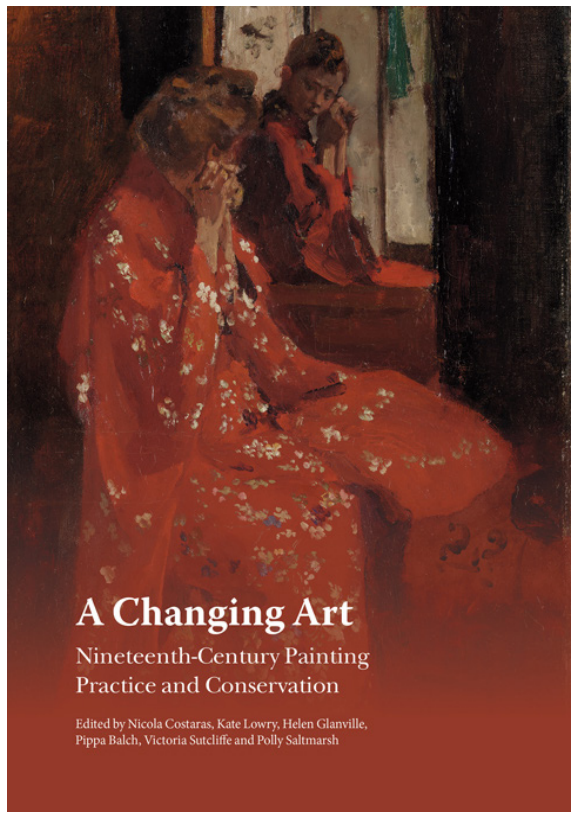

\title{
A Changing Art. Nineteenth-Century Painting Practice and Conservation
}

\author{
Ed. Por Nicola Costaras, Kate Lowry, Helen Glanville, \\ Pippa Balch, Victoria Sutcliffe y Polly Satlmarsh)
}

Londres: Archetype (en asociación con The British Association of Paintings Conservator-Restorers, BAPCR), 2017.

ISBN: 9781909492547

Dimensiones: 246 x $175 \mathrm{~mm}$

Páginas: 144

llustraciones en color

El pasado año la editorial Archetype editó las actas del Congreso Internacional organizado por la Asociación Británica de Conservadores-restauradores de Pintura el 7 de octubre de 2016. El congreso llevó por título $A$ Changing Art. Nineteenth-Century Painting Practice and Conservation $y$, como indica su nombre, tenía como objetivo reunir comunicaciones sobre un tema que considerado de gran interés por la escasez de estudios monográficos dedicados a la conservación y técnicas de la pintura en el siglo XIX. Pippa Balch, autora del prólogo y Presidenta de la Asociación Británica de Conservadores-Restauradores de Pintura, señala que eligieron ese tema por la importancia que tiene para los restauradores hoy en día ya que cada vez es más las pinturas del siglo XIX que están necesitadas de ser intervenidas para su conservación a medida que se van manifestando los efectos del envejeciendo. Conocer los materiales que las componen y los procedimientos técnicos con los que están hechas es sin duda un requisito fundamental para diagnosticar los problemas y proponer tratamientos para su conservación.

Son pinturas, como advierte muy acertadamente Balch, que presentan particulares desafíos al restaurador, desafíos que parten de unas características muy especiales en cuanto a materiales empleados y técnica de ejecución. En este siglo la industrialización y comercialización avanza considerablemente y se van introduciendo nuevos materiales (fibras textiles, imprimaciones, pigmentos sintéticos, barnices), lo que va a provocar procesos de envejecimiento y alteración con características diferentes a los de siglos anteriores. En el congreso se pretendía explorar las razones de esta complejidad y crear un foro en el que compartir distintas visiones e interpretaciones sobre cómo abordar la pintura del XIX. Las ponencias recogidas en esta publicación, de alta calidad y diversidad, proceden de diversos ámbitos, tanto del mundo privado, de museos, del mundo académico y otros.

El libro empieza con una introducción de Sally Woodcock (Hamilton Kerr Institute) en la que destaca la escasez de estudios sobre la técnica y los materiales de pintores decimonónicos británicos, algo que ya había puesto de relieve Joyce $\mathrm{H}$. Townsen en 2002 ('The Materials Used by British Oil Painters in the Nineteenth Century', Tate Papers, no.2, Autumn 2004 http://www.tate.org.uk/ research/publications/tate-papers/02/the-materialsused-by-british-oil-painters-in-the-nineteenthcentury, consultado el 22 de junio de 2018), seguido de las ponencias, unas de contenido más general y otras con estudios más específicos.

Algunos artículos se centran en la investigación en fuentes documentales, como el de misma autora de la introducción, Sally Woodcock, que trata sobre vendedores de colores en la época victoriana, "Keynote Address: Alteration, restoration and why pictures foam: what conservators can learn from Victorian artists' colourme". La gran especialista en pintura de este siglo aporta una revisión general de fuentes sobre materiales y técnicas de pintura al óleo y de las reconstrucciones de recetas a partir de estas fuentes, tema al que se ha venido dedicando largo tiempo y del que nos ha dejado trabajos esenciales. En su artículo "NineteenthCentury Oil Painting Materials and Techniques 
Research: A Review of Key Findings from Documentary Sources, Results from Reconstructions with Historically Appropriate Materials and Suggestions for Future Research marca unas líneas de investigación muy útiles para conducir nuevas propuestas.

La mayoría de las contribuciones tratan sobre la técnica de artistas concretos o escuelas, bien sobre sus necesidades de conservación, como Giovanni Boldini ("Giovanni Boldini: Technique and Conservation. A Systematic Scientific Study of Forty Paintings and Eight Watercolours", presentado por Fabio Frezzato, Gianluca Poldi, Enzo Savoia, Arianna Splendore, Delacroix ("Delacroix: Mid-Century Modern Master", por Adele Wright), George Hendrik Breitner ("George Hendrik Breitner at Work: A Joint Perspective on NineteenthCentury Artistic Practice", por Nienke Woltma y, Suzanne Veldink), la escuela de Barbizon ("The Barbizon Paintings at the National Gallery, London: A Technical Survey", a cargo de Gabriella Macaro), Ernst Victor Hareux ("Ernst Victor Hareux and the Barbizon Artists", presentado por Hayley Tomlinson, Sarah Herring, Gabriella Macaro), Alfred East ("The Conservation and Research of Two Paintings by Alfred East RA", por Michaela Straub), Rudolf Swoboda ("Observations on Rudolf Swoboda's Painting Technique", por Nele Bordt, Katy Saunders-Blessley) o Jacob Maris ("The Cleaning of a Solvent Sensitive Painting by Jacob Maris", por Lidwien Speleers). Otros se centran es la práctica de la restauración en el siglo XIX, como la de Jacob Simon sobre los trabajos realizados en obras de los museos públicos de Gran Bretaña ("Nineteenth Century Restoration in Public Galleries in Britain in the National Portrait Gallery"), o la de Roxane Sperber "The Retouching Practices of John Linnell and the Challenges Posed to Conservators: A Case Study of Hanson Toot, View in Dovedale".

Finalmente habría que señalar aquellos artículos sobre tipos de alteraciones que caractyerizan a los materiales de esta época: "'These pitchy pigments from their very nature never harden': Nineteenth-Century Perspective on Premature Cracking in Oil Paintings" de Nicola Costaras, que trata sobre el problema tan común en este siglo de los craquelados prematuros, u otros problemas como el artículo de Rosalind Whitehouse, "Oily Drops on the Window Pane".

Towsend, en la publicación de 2002 antes mencionada, contabilizaba que en 14 años solo se habían realizado estudios técnicos de 15 artistas británicos (añadiéndose luego otros ocho, según Woodcock). Si trasladamos esas cifras al panorama español, estas se reducen considerablemente, algo que merece ser tenido en cuenta pues los problemas de conservación en el caso español son igualmente críticos. La necesidad de promover investigaciones técnicas en torno a la pintura española de esta época es indiscutible. Sería una buena noticia que las instituciones, museos y colectivos profesionales promovieran encuentros en los que se den a conocer experiencias de trabajo e investigaciones multidisciplinares sobre la técnica y la conservación de pintura española en el siglo XIX.

Rocío Bruquetas Galán

Museo de América (Madrid) 